\title{
Anesthetic Pharmacology and the Morbidly Obese Patient
}

\author{
Jerry Ingrande $\cdot$ Hendrikus J. M. Lemmens
}

Published online: 13 December 2012

(C) Springer Science + Business Media New York 2012

\begin{abstract}
Anesthesiologists are increasingly being faced with treating obese patients. Physiologic and anthropometric changes associated with obesity-most notably increases in cardiac output, changes in tissue perfusion and increases in total body weight, lean body weight, and fat mass affect the pharmacokinetics (PK) of anesthetic agents. In addition, redundancy of airway tissue, obstructive and central sleep apnea and $\mathrm{CO}_{2}$ retention affect the pharmacodynamics (PD) of anesthetics and narrow the therapeutic window of numerous anesthetic drugs. Safe and effective pharmacologic management of the obese patient requires a thorough understanding of how obesity affects the PK and PD of anesthetics.
\end{abstract}

Keywords Obesity · Pharmacokinetics .

Pharmacodynamics . Total body weight $\cdot$ Lean body weight .

Volume of distribution - Clearance - Cardiac output .

Distribution $\cdot$ Peak effect $\cdot$ Elimination $\cdot$ Half-life

\section{Introduction}

The prevalence of obesity among adults in the United States is increasing. According to the Centers for Disease Control and Prevention, more than one-third of U.S. adults are obese $(35.7 \%)$ [1]. In addition, the incidence of obesity

J. Ingrande $(\varangle) \cdot$ H. J. M. Lemmens

Department of Anesthesia, Stanford University School

of Medicine, 300 Pasteur Drive Room H3580,

Stanford, CA 94305, USA

e-mail: jerryi@stanford.edu

H. J. M. Lemmens

e-mail: hlemmens@stanford.edu has increased dramatically over the last decade. By 2010, the number of states with an obesity rate of $30 \%$ or more had risen to twelve. By comparison, in the year 2000, no state had an obesity rate greater than $30 \%$ [2]. Obesity and the length of exposure to obesity have been shown to be risk factors for both number of hospital admissions and length of hospital stay [3, 4]. In 1998, the National Institutes of Health recommended bariatric surgery as the primary treatment of morbid obesity [5]. Since then, the number of bariatric surgeries has increased dramatically, although this amount has plateaued since 2006 [6]. Anesthesiologists are now managing obese patients-and their associated comorbidities-at an increasing rate. The increased risks of anesthesia in obese subjects have been described $[2,7,8]$. The physiologic and anthropometric changes associated with obesity likely affect the pharmacokinetics (PK) of anesthetic agents [9]. Obesity is associated with an increase in cardiac output and in total blood volume, which may alter drug distribution, peak concentration and clearance [7, 9]. In addition, increases in fatand lean-body mass and changes in tissue perfusion may affect the apparent volume of distribution of many anesthetic agents. Pathophysiology associated with obesity, including an increased prevalence of obstructive sleep apnea and $\mathrm{CO}_{2}$ retention, reduced functional residual capacity, and cardiac dysfunction, alter the pharmacodynamics (PD) of anesthetics. The result is a narrowing of the therapeutic index of anesthetic agents.

The narrow therapeutic indices of anesthetics require knowledge of how obesity affects drug PK/PD to ensure safe and effective dosing. However, the studies specifically addressing the effect of obesity on anesthetic drug management have been sparse or conflicting. The following is a review of the PK and PD of anesthetic agents in obese subjects. 


\section{Volume of Distribution and Clearance}

Obesity was once thought of as simply a disease of excess adiposity. Currently, it is understood that although all obese subjects share a common phenotype (adiposity), the excess adiposity of obesity is also associated with multiorgan system dysfunction. In order to understand the how obesity affects the PK and PD of anesthetic agents, it is necessary to understand the specific pathophysiologic changes associated with obesity.

Obesity is associated with an increase in total body weight (TBW), lean body weight (LBW), and fat mass. LBW accounts for $20-40 \%$ of the increase in TBW in obese subjects [10]. However, with increasing obesity, fat mass increases to a greater extent than LBW, and the ratio of LBW to TBW decreases [11]. The increase in fat mass has been shown to increase the volume of distribution of lipophilic drugs [12-14]. Central volume of distribution is the major pharmacokinetic parameter governing selection of a loading dose. It makes intuitive sense then to administer larger initial loading doses of drugs to obese individuals. However, plasma protein binding, cardiac output and tissue perfusion also play major roles in drug distribution. While obesity has not been shown to alter drug binding to albumin and $\alpha$-acid glycoprotein, there is an increase in cardiac output associated with obesity $[15,16]$. The increase in cardiac output is strongly related to the increase in LBW [17]. Cardiac output is a significant predictor of early distribution kinetics [18]. It can be debated whether a loading dose should be administered based on TBW to reflect the increase in volume of distribution or administered based on LBW to reflect the change in cardiac output.

The increase in cardiac output associated with obesity results in increased hepatic and renal blood flow. In addition, there are regional differences in the perfusion of adipose tissue. Abdominal and visceral fat receive less blood flow than subcutaneous adipose tissue [19, 20]. Obesity is associated with an increase in drug clearance $[18,21,22]$. However, recent studies are demonstrating that the effect of obesity on drug metabolism and clearance is dependent on the metabolic pathway. Obesity decreases clearance of drugs metabolized by the cytochrome P450 $3 \mathrm{~A} 4$ pathway, while drugs metabolized by 2D6, 2E1, 1A2, and 2C9 show higher clearance in obese versus non-obese individuals $[23,24]$.

\section{Intravenous Induction Agents}

Thiopental

After a single bolus dose, thiopental enjoys a rapid time to peak effect (loss of consciousness within 15-20 s) owing to its rapid distribution into the central nervous system [25]. Redistribution from the plasma to peripheral tissue explains the rapid offset of action. The distribution and redistribution of thiopental is largely governed by cardiac output [25]. In normal-weight subjects, thiopental shows 2- or 3-compartment kinetics with a steady-state volume of distribution of 2-3 L/kg and clearance of $3-4 \mathrm{~mL} / \mathrm{kg} / \mathrm{min}$. Volume of distribution is increased and elimination halflife is prolonged in obese subjects [26]. The increased volume of distribution in the obese is thought to be secondary to an increased fat mass. Simulations of thiopental concentrations in the obese demonstrate that after a single bolus dose, there is a $60 \%$ reduction in thiopental peak plasma concentration compared to normal-weight subjects [27]. Animal studies have demonstrated that distribution clearance of thiopental increases linearly with cardiac output [28]. With the increase in cardiac output associated with obesity, it is not surprising then that total clearance of thiopental is increased in obese versus lean subjects [26]. There is no difference in thiopental clearance between obese and lean subjects when normalized to total body weight.

\section{Propofol}

Propofol is a highly lipophilic hypnotic (octanol-water partition coefficient of 4,300) and is the most commonly used hypnotic in the bariatric population. Like thiopental, propofol's kinetics are highly dependent on cardiac output (perfusion limited). In normal-weight subjects, propofol has a high volume of distribution and clearance. It is primarily metabolized by the liver, however, its clearance exceeds hepatic blood flow, suggesting extra-hepatic metabolism. Propofol's high lipophilicity may suggest that the volume of distribution would be considerably higher in obese subjects compared to normal-weight subjects, owing to their higher fat mass. In addition, the higher cardiac output seen in obese subjects may increase clearance. In a study in which propofol was used for induction and maintenance of anesthesia in eight morbidly obese subjects, the volume of the central compartment was similar to non-obese subjects [29]. However, steady-state volume of distribution and clearance were found to increase linearly with total body weight [29]. When normalized to total body weight, these differences disappeared. Similarly, Cortinez et al. [30•] found that an allometric model using total body weight was superior to other size metrics when describing volume and clearance of propofol in morbidly obese subjects. Simulated propofol plasma target-controlled infusions using the Cortinez model and the Marsh model $\left[30^{\bullet}, 31\right]$ (scaled to total body weight) showed similar infusion rate profiles.

With steady-state volume and clearance increasing linearly with total body weight, it has been suggested that 
maintenance doses of propofol be based upon a total body weight scalar as it is in lean subjects $[29,30 \bullet$. However, La Colla et al. [32] found administration of propofol in obese subjects via a weight-adjusted or TBW-scaled infusion resulted in significant performance bias for both groups. There was no statistically significant difference in performance bias between the weight-adjusted and TBW models. These authors suggested therefore that propofol be titrated to effect in obese subjects.

\section{Etomidate}

Etomidate is associated with minimal cardiovascular suppression when administered as an intravenous bolus for induction of anesthesia. It is therefore widely considered to be the induction agent of choice in hemodynamically unstable patients. Etomidate is associated with a transient suppression of the adrenocortical axis, and this property has fueled controversy as to whether acutely ill patients are exposed to an increased risk of morbidity and mortality after its use. However, recent studies have refuted these claims [33, 34].

In lean subjects, etomidate shows three-compartment kinetics with rapid distribution with the central compartment. It has a time to peak effect of 30-60 s. Its rapid offset is owed to its rapid redistribution to the peripheral tissues. Etomidate's clearance $(11-25 \mathrm{~mL} / \mathrm{min} / \mathrm{kg}$ ) approximates hepatic blood flow [35]. Its pharmacokinetic properties have not been established in obese subjects. However, since etomidate has similar pharmacokinetic and physicochemical properties as propofol, its pharmacokinetic profile is likely to behave similarly to propofol in obese subjects.

\section{Dexmedetomidine}

Dexmedetomidine is a highly selective $\alpha-2$ agonist with an $\alpha-2: \alpha-1$ selectivity ratio of $1,500: 1$. It is used for procedural sedation and as an adjunct to general anesthesia due to its sedative, analgesic and anxiolytic effects. Its use as an adjunct to general anesthesia for bariatric surgery has been advocated because of reductions in peri- and postoperative opioid requirements [36]. In addition, dexmedetomidine has been found to lower volatile anesthetic requirements, and attenuate hemodynamic stability when used during laparoscopic bariatric surgery [37]. However, the use of dexmedetomidine failed to improve quality of recovery or speed time to hospital discharge [36].

There have been no studies to date analyzing the effects of obesity on the PK/PD of dexmedetomidine. An infusion rate of $0.2 \mu \mathrm{g} \mathrm{kg} \mathrm{h}^{-1}$ has been recommended to avoid bradycardia and hypotension [36].

\section{Opioids}

Obese subjects are at increased risk for opioid-induced respiratory depression and airway obstruction due to their pathophysiology [38]. With increasing obesity, there is an increased incidence for obstructive sleep apnea, hypoxia, and central sleep apnea. In addition, redundant pharyngeal tissue places these patients at risk for upper airway obstruction. Upper airway obstruction, OSA, and hypoxia are increased following the administration of opioids [39, 40••, 41]. Together, these changes narrow the therapeutic window for opioids.

\section{Fentanyl}

Fentanyl is a synthetic opioid with a potency approximately 100 -times that of morphine. It is the most widely used opioid in anesthetic practice. Fentanyl has a predictable time to peak effect of 3-5 min. Its short duration of action following a single bolus dose is attributed to rapid redistribution from the central nervous system into the plasma and peripheral tissues. Despite its short duration of action after a single bolus dose, after prolonged administration (i.e. continuous infusions) saturation of the peripheral compartments occurs. Decrement in plasma concentration becomes more dependent on metabolism and elimination rather than redistribution. Numerous PK/PD models of fentanyl have been constructed, however none of these have been validated in obese individuals [42-44].

Fentanyl has a large volume of distribution due mainly to its high lipophilicity. Theoretically, obese subjects would have a larger volume of distribution due to their larger amount of adipose tissue, effectively lowering the plasma concentration after a single bolus dose. While obese subjects do have a lower plasma concentration during the early distribution phase, this is related to their higher cardiac output, rather than an increased volume of distribution [45]. The clearance of fentanyl is significantly increased in obese subjects [46]. The relationship between clearance and total body weight is nonlinear, however, fentanyl clearance increases linearly with "pharmacokinetic mass", which is highly correlated to lean body weight [46].

\section{Alfentanil}

Alfentanil is a fentanyl derivative with one-tenth the potency and lower lipophilicity. It has a faster time to peak effect (1.4 min), largely due to its lower pKa. The lower lipophilicity of alfentanil decreases its effective volume of distribution compared to fentanyl. Like fentanyl, the increased cardiac output in obese subjects lowers the plasma concentration of alfentanil during the early distribution phase [43, 45]. Obese individuals should have a theoretically increased volume of distribution and longer terminal elimination 
half-time compared to normal weight subjects. No validated PK/PD models for alfentanil exist for obese individuals.

\section{Sufentanil}

Sufentanil is a synthetic derivative of fentanyl that is ten times as potent. It is the most highly lipophilic opioid. The apparent volume of distribution and elimination half-life of sufentanil both increase with obesity [47]. However, sufentanil clearance is similar in obese subjects compared to normal-weight subjects [47]. Slepchenko et al. [48] validated the performance of sufentanil target-controlled infusions using PK models of sufentanil derived from normal-weight subjects. These authors found that PK models over-predicted sufentanil plasma concentrations in obese individuals. This over-prediction was found to increase with increasing BMI.

\section{Remifentanil}

A highly potent synthetic opioid, remifentanil is characterized by a rapid time to peak effect (approximately $1 \mathrm{~min}$ ) and rapid offset of action. Remifentanil's chemical structure contains an ester linkage. The drug undergoes rapid metabolism via non-specific tissue and plasma esterases, resulting in organ-independent clearance. This rapid metabolism accounts for its rapid termination of effect, even after prolonged administration. Remifentanil is commonly administered as a continuous infusion for sedation or in combination with an intravenous hypnotic agent or inhalational anesthetic for general anesthesia. Simulations of remifentanil blood concentrations in obese subjects demonstrated that obese individuals administered a remifentanil infusion based upon LBW had similar plasma concentrations as normal weight subjects given the drug based upon TBW [49]. In addition, infusions based upon total body weight resulted in significantly higher plasma concentrations. Remifentanil's pharmacokinetic profile has popularized its use as an analgesic in obese subjects. However, when comparing remifentanil and sufentanil target controlled infusions in obese subjects undergoing laparoscopic gastrectomy, Bidgoli et al. [50••] demonstrated that subjects given remifentanil had quicker times to extubation but significantly higher scores on the visual analogue pain scale and required more rescue analgesia in the immediate recovery period. Similarly, De Baerdemaeker et al. [51] showed that remifentanil offered no significant advantages in recovery profile compared to sufentanil in obese subjects undergoing laparoscopic gastric banding. In addition, the subjects given remifentanil had higher opioid consumption in the immediate postoperative period. Despite remifentanil's forgiving termination of effect, its use may be questioned as an adjunct to general anesthesia in obese subjects undergoing bariatric surgery.

\section{Inhalational Agents}

Isoflurane

Of the major inhalational agents used today in clinical practice, isoflurane is the most lipid-soluble. Its high lipid solubility, together with the increased adipose tissue mass found in obese subjects, would theoretically increase peripheral distribution of isoflurane and result in increased time to recovery. However, obese subjects given 0.6 minimum alveolar concentration (MAC) of isoflurane for surgery lasting $2-4 \mathrm{~h}$ showed similar recovery profiles as non-obese subjects [52]. In addition, the time constant for isoflurane to reach equilibrium with adipose tissue is approximately 2,110 min, much longer than most surgical cases [53]. This property, coupled with low adipose tissue blood flow, diminish the effect of excess adiposity on isoflurane distribution and recovery. In their study comparing the pharmacokinetics of volatile agents in obese and lean individuals, Lemmens et al. [52] demonstrated a statistical but clinically insignificant effect of obesity on isoflurane uptake (Fig. 1).

\section{Sevoflurane}

Sevoflurane has a blood-gas partition coefficient of 0.65 making it half as soluble as isoflurane, resulting in a more rapid uptake and elimination in obese subjects. The lower solubility of sevoflurane offers the theoretical advantage of a more rapid uptake and decreased peripheral tissue distribution, leading to a faster recovery. In a randomized clinical trial comparing uptake and recovery profiles of sevoflurane compared to isoflurane in obese subjects, Torri

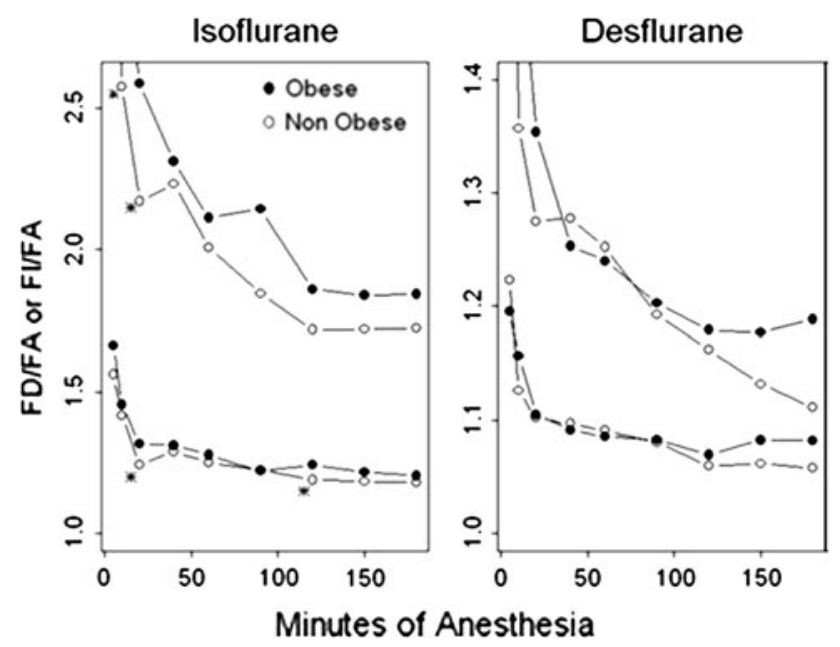

Fig. 1 Effect of obesity on FD/FA and FI/FA ratios for isoflurane and desflurane. FD/FA will always be higher than FI/FA. Obesity modestly affects FD/FA and FI/FA for isoflurane but not desflurane. From Lemmens et al. [52] with permission from Wolters Kluwer Health 
et al. [54] showed a more rapid wash-in and wash-out of sevoflurane compared to isoflurane in obese subjects. Faster recovery was seen only within the first minute of discontinuation of the drug. However, in a similar study, these same authors reported significantly faster recovery and earlier times to PACU discharge following administration of sevoflurane compared to isoflurane in obese subjects undergoing gastric banding [55].

\section{Desflurane}

Desflurane is the least soluble volatile anesthetic in clinical use with a blood-gas partition coefficient of 0.45 . Because of its low solubility, desflurane has limited distribution to peripheral tissue. The time constant for equilibrium with adipose tissue for desflurane is approximately 1,350 min [53]. Recovery after desflurane is faster than isoflurane in both obese and non-obese subjects $[52,56]$. A meta-analysis of six studies comparing recovery profiles of desflurane versus sevoflurane demonstrated that desflurane was superior to sevoflurane with regard to time to eye-opening and time to obeying command [57]. However, this study failed to show superiority of desflurane over sevoflurane in times to PACU discharge. While some studies have shown faster emergence with desflurane over sevoflurane in obese subjects [56, 58, 59], others have shown no difference between the two drugs $[60,61]$.

\section{Neuromuscular Blockers}

\section{Succinylcholine}

Succinylcholine is currently the only non-depolarizing neuromuscular blocker in clinical use. It is characterized by a rapid onset of action and an ultra-rapid duration of effect, owing to its metabolism by pseudocholinesterase. Succinylcholine is still considered to be the neuromuscular blocking agent of choice in obese subjects, as the rapid onset of action facilitates rapid tracheal intubation, and rapid duration of effect allows quick return of spontaneous ventilation. In normal-weight subjects, the ED95 of succinylcholine in the absence of nitrous oxide is $0.5 \mathrm{mg} / \mathrm{kg}$ [62]. Nitrous oxide and opioids potentiate succinylcholine's effect, and in the presence of nitrous oxide and opioids the ED95 is decreased to $0.3-0.35 \mathrm{mg} / \mathrm{kg}$ [63]. In obese subjects, the amount of pseudocholinesterase is increased [64]. This raises the dose requirement necessary to achieve optimal intubating conditions in obese individuals. In a study analyzing the optimal dosing strategy of succinylcholine in morbidly obese subjects, Lemmens and Brodsky determined that a dose of $1 \mathrm{mg} / \mathrm{kg}$ TBW resulted in optimal intubating conditions in this patient population [65]. Despite the rapid metabolism of succinylcholine by pseudocholinesterase, the duration of effect is dose-dependent, and doses of $1 \mathrm{mg} / \mathrm{kg}$ TBW were found to take 8-12 min for dissipation of effect [63]. Dose administered was found to explain close to $60 \%$ of the variability in duration of effect [63].

\section{Pancuronium}

Pancuronium is an aminosteroid neuromuscular blocker with a very long time of onset $(5 \mathrm{~min})$ and duration of effect (60-90 min). Obese subjects have an increased extracellular fluid volume, and therefore have an increased volume of distribution for pancuronium compared to lean subjects. When compared to normal-weight subjects, obese subjects require an increased amount of pancuronium for maintenance of twitch depression [66]. There is no difference in dose requirements when corrected for body surface area. With the introduction and widespread use of the intermediate-duration neuromuscular blocking agents, the use of pancuronium, especially in obese subjects, has waned.

\section{Vecuronium}

Vecuronium is an aminosteroid neuromuscular relaxant with an intermediate duration of effect. After a single intubating dose of $0.1 \mathrm{mg} / \mathrm{kg}$, vecuronium has a time of peak effect of approximately $3 \mathrm{~min}$, and a duration of effect of 45-60 min. Although obese subjects have an increased extracellular fluid volume compared to normal-weight subjects, there is no change in the volume of distribution of vecuronium. In a study comparing PK and PD variables of vecuronium in obese versus non-obese subjects, Schwartz et al. [67] found no difference in PK variables between the two groups. In addition, these same authors found a prolonged duration of effect in obese subjects [67]. Similarly, after a dose of $0.1 \mathrm{mg} / \mathrm{kg}$ TBW of vecuronium was given, Suzuki et al. [68] demonstrated a prolonged time to spontaneous recovery of $25 \%$ twitch in obese subjects (68.4 min) compared to normal weight subjects (41 min). Vecuronium is eliminated by hepatic clearance and biliary excretion. Weinstein et al. [69] postulated that the prolonged recovery of vecuronium in obese subjects is likely secondary to impaired hepatic clearance and an overdose effect when the drug is given based upon TBW.

\section{Rocuronium}

Rocuronium is an aminosteroid neuromuscular blocking agent. Its chemical structure is characterized by a quaternary ammonium group, limiting its distribution to peripheral tissue. Despite the higher extracellular fluid volume in obese subjects, the PK of rocuronium are not altered. In a study comparing PK/PD of rocuronium in obese and 
normal weight subjects, Puhringer et al. [70] found no differences in volume of distribution, clearance, mean residence time, and distribution and elimination half-times between obese and control subjects. In addition, recovery profiles were similar between the two groups [70]. In a similar study examining only the PD of rocuronium in obese subjects, these same authors showed no difference in spontaneous recovery or induced recovery between obese and normal weight subjects [71]. Time to $25 \%$ recovery was slightly prolonged in obese subjects [71].

\section{Neuromuscular Blocking Reversal Agents}

Obese subjects show a prolonged spontaneous recovery following administration of non-depolarizing neuromuscular blocking drugs [67-69, 72]. Moreover, obesity increases the risk of post-operative respiratory complications [73, 74]. In addition, diaphragmatic tone and endexpiratory lung volumes are decreased at the onset of sleep in obese versus normal weight subjects [75]. Therefore, pharmacologic reversal with a neuromuscular blocking antagonist is recommended to avoid post-operative residual curarization and adverse respiratory events.

Neostigmine, an acetylcholinesterase inhibitor, has long been used to facilitate recovery of neuromuscular function. In obese subjects, recovery of neuromuscular functioneven after full reversal with neostigmine-is incomplete compared to normal-weight subjects. Obese and normalweight subjects given neostigmine for reversal of vecuronium-induced neuromuscular blockade had similar times to achieve a train-of-four ratio of 0.7 [68]. However, obese subjects showed a four-fold increase in time to achieve a train-of-four ratio of 0.9 (25.9 vs. $6.9 \mathrm{~min}$ ) [68]. A recent study showed that obese subjects given neostigmine following rocuronium had residual curarization in the recovery unit [76•].

Recently, sugammadex has been introduced as an alternative to neostigmine for reversal of neuromuscular blockade. Sugammadex is a dextrin molecule with a lipophilic core and hydrophilic exterior that specifically binds free rocuronium molecules. It also has modest affinity for vecuronium and even less affinity for pancuronium. Sugammadex allows rapid, full reversal of neuromuscular blockade, without the autonomic side effects associated with neostigmine. A direct comparison of sugammadex with neostigmine for reversal of rocuronium-induced neuromuscular blockade in morbidly obese subjects showed that subjects given sugammadex had a faster time to recovery of a train-of-four ratio of 0.9 (2.7 vs. $9.6 \mathrm{~min}$ ) [76•]. In addition, train-of-four ratios in the post-operative recovery unit were 109.8 and $85.5 \%$ for subjects given sugammadex and neostigmine, respectively [76 ${ }^{\bullet}$. There have been no studies examining the PK/PD of sugammadex specific to the obese population. However, a recent study showed a limited but clinically insignificant effect of body weight on the PK of sugammadex [77]. Whether TBW or ideal body weight (IBW) should be used as a dosing scalar for sugammadex in obese subjects has been debated. Van Lancker et al. [78] concluded that IBW be used for dosing sugammadex in obese individuals. However, recurarization after sugammadex administration has been reported [79]. This has led others to suggest that sugammadex be administered on the basis of TBW to ensure adequate reversal of neuromuscular blockade $[80,81]$.

\section{Conclusion}

The incidence and prevalence of obesity continues to increase globally. Anesthesiologists are being faced with these patients at an increasing rate. The pathophysiology associated with obesity, most notably anthropometric changes and derangements in cardio-pulmonary physiology, narrow the therapeutic indices of many anesthetic agents. These changes place these patients at risk for anesthetic-related complications. Knowledge of how obesity affects the PK and PD of anesthetics is necessary to derive safe and effective dosing strategies for these patients.

Disclosure No potential conflicts of interest relevant to this article were reported

\section{References}

Papers of particular interest, published recently, have been highlighted as:

- Of importance

•• Of major importance

1. Shields M, Carroll MD, Ogden CL. Adult obesity prevalence in Canada and the United States. NCHS Data Brief. 2011;56:1-8.

2. Candiotti K, Sharma S, Shankar R. Obesity, obstructive sleep apnoea, and diabetes mellitus: anaesthetic implications. $\mathrm{Br} \mathrm{J}$ Anaesth. 2009;103(Suppl 1):i23-30.

3. Quesenberry CP Jr, Caan B, Jacobson A. Obesity, health services use, and health care costs among members of a health maintenance organization. Arch Intern Med. 1998;158:466-72.

4. Schafer MH, Ferraro KF. Obesity and hospitalization over the adult life course: does duration of exposure increase use? J Health Soc Behav. 2007;48:434-49.

5. Pi-Sunyer FX. Clinical guidelines on the identification, evaluation, and treatment of overweight and obesity in adults-the evidence report. National Institutes of Health. Obes Res. 1998;6 Suppl 2:51S-209S.

6. Livingston $\mathrm{EH}$. The incidence of bariatric surgery has plateaued in the U.S. Am J Surg. 2010;200:378-85.

7. Adams JP, Murphy PG. Obesity in anaesthesia and intensive care. Br J Anaesth. 2000;85:91-108. 
8. Shenkman Z, Shir Y, Brodsky JB. Perioperative management of the obese patient. Br J Anaesth. 1993;70:349-59.

9. Cheymol G. Effects of obesity on pharmacokinetics implications for drug therapy. Clin Pharmacokinet. 2000;39:215-31.

10. Forbes GB, Welle SL. Lean body mass in obesity. Int J Obes. 1983;7:99-107.

11. Janmahasatian S, Duffull SB, Ash S, Ward LC, Byrne NM, Green B. Quantification of lean bodyweight. Clin Pharmacokinet. 2005;44:1051-65.

12. Casati A, Putzu M. Anesthesia in the obese patient: pharmacokinetic considerations. J Clin Anesth. 2005;17:134-45.

13. Kendrick JG, Carr RR, Ensom MH. Pharmacokinetics and drug dosing in obese children. J Pediatr Pharmacol Ther. 2010;15: 94-109.

14. Shi S, Klotz U. Age-related changes in pharmacokinetics. Curr Drug Metab. 2011;12:601-10.

15. Abernethy DR, Greenblatt DJ, Divoll M, Smith RB, Shader RI. The influence of obesity on the pharmacokinetics of oral alprazolam and triazolam. Clin Pharmacokinet. 1984;9:177-83.

16. Benedek IH, Fiske WD 3rd, Benedek IH, Griffen WO, Bell RM, Blouin RA, McNamara PJ. Serum alpha 1-acid glycoprotein and the binding of drugs in obesity. Br J Clin Pharmacol. 1983; $16: 751-4$

17. Collis T, Devereux RB, Roman MJ, de Simone G, Yeh J, Howard BV, Fabsitz RR, Welty TK. Relations of stroke volume and cardiac output to body composition: the strong heart study. Circulation. 2001;103:820-5.

18. Avram MJ, Krejcie TC. Using front-end kinetics to optimize target-controlled drug infusions. Anesthesiology. 2003;99: 1078-86.

19. Virtanen KA, Lonnroth P, Parkkola R, Peltoniemi P, Asola M, Viljanen T, Tolvanen T, Knuuti J, Ronnemaa T, Huupponen R, Nuutila P. Glucose uptake and perfusion in subcutaneous and visceral adipose tissue during insulin stimulation in nonobese and obese humans. J Clin Endocrinol Metab. 2002;87:3902-10.

20. Larsen OA, Lassen NA, Quaade F. Blood flow through human adipose tissue determined with radioactive xenon. Acta Physiol Scand. 1966;66:337-45.

21. Salazar DE, Corcoran GB. Predicting creatinine clearance and renal drug clearance in obese patients from estimated fat-free body mass. Am J Med. 1988;84:1053-60.

22. Stokholm KH, Brochner-Mortensen J, Hoilund-Carlsen PF. Increased glomerular filtration rate and adrenocortical function in obese women. Int J Obes. 1980;4:57-63.

23. Brill MJ, Diepstraten J, van Rongen A, van Kralingen S, van den Anker JN, Knibbe CA. Impact of obesity on drug metabolism and elimination in adults and children. Clin Pharmacokinet. 2012;51:277-304.

24. Kotlyar M, Carson SW. Effects of obesity on the cytochrome P450 enzyme system. Int J Clin Pharmacol Ther. 1999;37:8-19.

25. Price HL. A dynamic concept of the distribution of thiopental in the human body. Anesthesiology. 1960;21:40-5.

26. Jung D, Mayersohn M, Perrier D, Calkins J, Saunders R. Thiopental disposition in lean and obese patients undergoing surgery. Anesthesiology. 1982;56:269-74.

27. Wada DR, Bjorkman S, Ebling WF, Harashima H, Harapat SR, Stanski DR. Computer simulation of the effects of alterations in blood flows and body composition on thiopental pharmacokinetics in humans. Anesthesiology. 1997;87:884-99.

28. Weiss M, Krejcie TC, Avram MJ. A minimal physiological model of thiopental distribution kinetics based on a multiple indicator approach. Drug Metab Dispos. 2007;35:1525-32.

29. Servin F, Farinotti R, Haberer JP, Desmonts JM. Propofol infusion for maintenance of anesthesia in morbidly obese patients receiving nitrous oxide. A clinical and pharmacokinetic study. Anesthesiology. 1993;78:657-65.
30. - Cortinez LI, Anderson BJ, Penna A, Olivares L, Munoz HR, Holford NH, Struys MM, Sepulveda P. Influence of obesity on propofol pharmacokinetics: derivation of a pharmacokinetic model. Br J Anaesth. 2010;105:448-56. This is one of the first studies examining the effect of obesity on the pharmacokinetics of propofol. Allometric scaling was used to create a valid model characterizing the kinetics of propofol in the obese population.

31. Marsh B, White M, Morton N, Kenny GN. Pharmacokinetic model driven infusion of propofol in children. Br J Anaesth. 1991;67:41-8.

32. La Colla L, Albertin A, La Colla G, Ceriani V, Lodi T, Porta A, Aldegheri G, Mangano A, Khairallah I, Fermo I. No adjustment vs. adjustment formula as input weight for propofol target-controlled infusion in morbidly obese patients. Eur J Anaesthesiol. 2009;26:362-9.

33. Morel J, Salard M, Castelain C, Bayon MC, Lambert P, Vola M, Auboyer C, Molliex S. Haemodynamic consequences of etomidate administration in elective cardiac surgery: a randomized double-blinded study. Br J Anaesth. 2011;107:503-9.

34. Ehrman R, Wira C, Lomax A, Hayward A, Marcelin J, Ellis T, Przyklenk K, Volturo G, Mullen M. Etomidate use in severe sepsis and septic shock patients does not contribute to mortality. Intern Emerg Med. 2011;6:253-7.

35. Davis PJ, Cook DR. Clinical pharmacokinetics of the newer intravenous anaesthetic agents. Clin Pharmacokinet. 1986;11:18-35.

36. Tufanogullari B, White PF, Peixoto MP, Kianpour D, Lacour T, Griffin J, Skrivanek G, Macaluso A, Shah M, Provost DA. Dexmedetomidine infusion during laparoscopic bariatric surgery: the effect on recovery outcome variables. Anesth Analg. 2008;106:1741-8.

37. Feld JM, Hoffman WE, Stechert MM, Hoffman IW, Ananda RC. Fentanyl or dexmedetomidine combined with desflurane for bariatric surgery. J Clin Anesth. 2006;18:24-8.

38. Benumof JL. Obesity, sleep apnea, the airway and anesthesia. Curr Opin Anaesthesiol. 2004;17:21-30.

39. Drummond GB. Comparison of decreases in ventilation caused by enflurane and fentanyl during anaesthesia. $\mathrm{Br} \mathrm{J}$ Anaesth. 1983;55:825-35.

40. • Yue HJ, Guilleminault C. Opioid medication and sleep-disordered breathing. Med Clin North Am. 2010;94:435-46. This is an important review article illustrating the adverse events and risks associated with opioid administration to patients with sleep-disordered breathing. There is a high prevalence of sleep-disordered breathing in the obese population, placing these patients at increased risk for adverse respiratory events associated with opioids.

41. Bennett JA, Abrams JT, Van Riper DF, Horrow JC. Difficult or impossible ventilation after sufentanil-induced anesthesia is caused primarily by vocal cord closure. Anesthesiology. 1997;87:1070-4.

42. McClain DA, Hug CC Jr. Intravenous fentanyl kinetics. Clin Pharmacol Ther. 1980;28:106-14.

43. Scott JC, Stanski DR. Decreased fentanyl and alfentanil dose requirements with age. A simultaneous pharmacokinetic and pharmacodynamic evaluation. J Pharmacol Exp Ther. 1987;240: 159-66.

44. Shafer SL, Varvel JR, Aziz N, Scott JC. Pharmacokinetics of fentanyl administered by computer-controlled infusion pump. Anesthesiology. 1990;73:1091-102.

45. Bjorkman S, Wada DR, Stanski DR. Application of physiologic models to predict the influence of changes in body composition and blood flows on the pharmacokinetics of fentanyl and alfentanil in patients. Anesthesiology. 1998;88:657-67.

46. Shibutani K, Inchiosa MA Jr, Sawada K, Bairamian M. Pharmacokinetic mass of fentanyl for postoperative analgesia in lean and obese patients. Br J Anaesth. 2005;95:377-83. 
47. Schwartz AE, Matteo RS, Ornstein E, Young WL, Myers KJ. Pharmacokinetics of sufentanil in obese patients. Anesth Analg. 1991;73:790-3.

48. Slepchenko G, Simon N, Goubaux B, Levron JC, Le Moing JP, Raucoules-Aime M. Performance of target-controlled sufentanil infusion in obese patients. Anesthesiology. 2003;98:65-73.

49. Egan TD, Huizinga B, Gupta SK, Jaarsma RL, Sperry RJ, Yee JB, Muir KT. Remifentanil pharmacokinetics in obese versus lean patients. Anesthesiology. 1998;89:562-73.

50. •• Bidgoli J, Delesalle S, De Hert SG, Reiles E, Van der Linden PJ. A randomised trial comparing sufentanil versus remifentanil for laparoscopic gastroplasty in the morbidly obese patient. Eur J Anaesthesiol. 2011;28:120-4. The use of remifentanil for perioperative analgesia has been popular because of its rapid clearance. It facilitates rapid emergence from analgesia. This study illustrates that accurate administration of sufentanil (via target controlled infusion) improves post-operative outcomes compared to remifentanil, and minimizes post-operative opioid use.

51. De Baerdemaeker LE, Jacobs S, Pattyn P, Mortier EP, Struys MM. Influence of intraoperative opioid on postoperative pain and pulmonary function after laparoscopic gastric banding: remifentanil TCI vs sufentanil TCI in morbid obesity. Br J Anaesth. 2007;99:404-11.

52. Lemmens HJ, Saidman LJ, Eger EI 2nd, Laster MJ. Obesity modestly affects inhaled anesthetic kinetics in humans. Anesth Analg. 2008;107:1864-70.

53. Yasuda N, Lockhart SH, Eger EI 2nd, Weiskopf RB, Johnson BH, Freire BA, Fassoulaki A. Kinetics of desflurane, isoflurane, and halothane in humans. Anesthesiology. 1991;74:489-98.

54. Torri G, Casati A, Comotti L, Bignami E, Santorsola R, Scarioni $\mathrm{M}$. Wash-in and wash-out curves of sevoflurane and isoflurane in morbidly obese patients. Minerva Anestesiol. 2002;68:523-7.

55. Torri G, Casati A, Albertin A, Comotti L, Bignami E, Scarioni M, Paganelli M. Randomized comparison of isoflurane and sevoflurane for laparoscopic gastric banding in morbidly obese patients. J Clin Anesth. 2001;13:565-70.

56. De Baerdemaeker LE, Struys MM, Jacobs S, Den Blauwen NM, Bossuyt GR, Pattyn P, Mortier EP. Optimization of desflurane administration in morbidly obese patients: a comparison with sevoflurane using an 'inhalation bolus' technique. Br J Anaesth. 2003;91:638-50.

57. Gupta A, Stierer T, Zuckerman R, Sakima N, Parker SD, Fleisher LA. Comparison of recovery profile after ambulatory anesthesia with propofol, isoflurane, sevoflurane and desflurane: a systematic review. Anesth Analg. 2004;98:632-41 (table of contents).

58. Strum EM, Szenohradszki J, Kaufman WA, Anthone GJ, Manz IL, Lumb PD. Emergence and recovery characteristics of desflurane versus sevoflurane in morbidly obese adult surgical patients: a prospective, randomized study. Anesth Analg. 2004;99:1848-53 (table of contents).

59. La Colla L, Albertin A, La Colla G, Mangano A. Faster wash-out and recovery for desflurane vs sevoflurane in morbidly obese patients when no premedication is used. $\mathrm{Br} \mathrm{J}$ Anaesth. 2007;99:353-8.

60. Arain SR, Barth CD, Shankar H, Ebert TJ. Choice of volatile anesthetic for the morbidly obese patient: sevoflurane or desflurane. J Clin Anesth. 2005;17:413-9.

61. Vallejo MC, Sah N, Phelps AL, O'Donnell J, Romeo RC. Desflurane versus sevoflurane for laparoscopic gastroplasty in morbidly obese patients. J Clin Anesth. 2007;19:3-8.

62. Szalados JE, Donati F, Bevan DR. Nitrous oxide potentiates succinylcholine neuromuscular blockade in humans. Anesth Analg. 1991;72:18-21.

63. Vanlinthout LE, van Egmond J, de Boo T, Lerou JG, Wevers RA, Booij LH. Factors affecting magnitude and time course of neuromuscular block produced by suxamethonium. Br J Anaesth. 1992;69:29-35.

64. Bentley JB, Borel JD, Vaughan RW, Gandolfi AJ. Weight, pseudocholinesterase activity, and succinylcholine requirement. Anesthesiology. 1982;57:48-9.

65. Lemmens HJ, Brodsky JB. The dose of succinylcholine in morbid obesity. Anesth Analg. 2006;102:438-42.

66. Tsueda K, Warren JE, McCafferty LA, Nagle JP. Pancuronium bromide requirement during anesthesia for the morbidly obese. Anesthesiology. 1978;48:438-9.

67. Schwartz AE, Matteo RS, Ornstein E, Halevy JD, Diaz J. Pharmacokinetics and pharmacodynamics of vecuronium in the obese surgical patient. Anesth Analg. 1992;74:515-8.

68. Suzuki T, Masaki G, Ogawa S. Neostigmine-induced reversal of vecuronium in normal weight, overweight and obese female patients. Br J Anaesth. 2006;97:160-3.

69. Weinstein JA, Matteo RS, Ornstein E, Schwartz AE, Goldstoff $M$, Thal G. Pharmacodynamics of vecuronium and atracurium in the obese surgical patient. Anesth Analg. 1988;67:1149-53.

70. Puhringer FK, Keller C, Kleinsasser A, Giesinger S, Benzer A. Pharmacokinetics of rocuronium bromide in obese female patients. Eur J Anaesthesiol. 1999;16:507-10.

71. Puhringer FK, Khuenl-Brady KS, Mitterschiffthaler G. Rocuronium bromide: time-course of action in underweight, normal weight, overweight and obese patients. Eur J Anaesthesiol Suppl. 1995; 11:107-10.

72. Leykin Y, Pellis T, Lucca M, Lomangino G, Marzano B, Gullo A. The pharmacodynamic effects of rocuronium when dosed according to real body weight or ideal body weight in morbidly obese patients. Anesth Analg. 2004;99:1086-9 (table of contents).

73. Ahmad S, Nagle A, McCarthy RJ, Fitzgerald PC, Sullivan JT, Prystowsky J. Postoperative hypoxemia in morbidly obese patients with and without obstructive sleep apnea undergoing laparoscopic bariatric surgery. Anesth Analg. 2008;107:138-43.

74. Hans GA, Lauwick S, Kaba A, Brichant JF, Joris JL. Postoperative respiratory problems in morbidly obese patients. Acta Anaesthesiol Belg. 2009;60:169-75.

75. Stadler DL, McEvoy RD, Bradley J, Paul D, Catcheside PG. Changes in lung volume and diaphragm muscle activity at sleep onset in obese obstructive sleep apnea patients vs. healthy-weight controls. J Appl Physiol. 2010;109:1027-36.

76. • Gaszynski T, Szewczyk T, Gaszynski W. Randomized comparison of sugammadex and neostigmine for reversal of rocuronium-induced muscle relaxation in morbidly obese undergoing general anaesthesia. Br J Anaesth. 2012;108:236-9. This study illustrates that postoperative recurarization may still occur despite full reversal of neuromuscular blockade with neostigmine. Full reversal of neuromuscular blockade, and vigilance for post-operative recurarization are necessary for safe therapy of obese subjects.

77. Kleijn HJ, Zollinger DP, van den Heuvel MW, Kerbusch T. Population pharmacokinetic-pharmacodynamic analysis for sugammadex-mediated reversal of rocuronium-induced neuromuscular blockade. Br J Clin Pharmacol. 2011;72:415-33.

78. Van Lancker P, Dillemans B, Bogaert T, Mulier JP, De Kock M, Haspeslagh M. Ideal versus corrected body weight for dosage of sugammadex in morbidly obese patients. Anaesthesia. 2011;66: $721-5$.

79. Le Corre F, Nejmeddine S, Fatahine C, Tayar C, Marty J, Plaud B. Recurarization after sugammadex reversal in an obese patient. Can J Anaesth. 2011;58:944-7.

80. Sabate A, Llaurado S. Ideal versus corrected body weight for dosage of sugammadex in morbidly obese patients. Anaesthesia. 2012;67:682. author reply 682-3.

81. Carron M, Freo U, Parotto E, Ori C. The correct dosing regimen for sugammadex in morbidly obese patients. Anaesthesia. 2012;67:298-9. 